\title{
Research and System Design of Traceability System for Food Safety
}

\author{
Yanbai Wang and Lu Tan ${ }^{*}$ \\ Changchun University Changchun Jilin China \\ ${ }^{*}$ Corresponding author
}

\begin{abstract}
Now the food industry has become more and more customers as the center, so the need for faster response time to deal with food safety incidents. The current food labeling system does not guarantee that the food is authentic, high quality and safety. Good traceability system helps to reduce the production and distribution of unsafe or poor quality products, so as to minimize the potential negative effects and product recall. As a tool to ensure food safety and quality, so as to obtain the trust of consumers. The traceability system of safety and quality in food supply chain is studied in this paper.
\end{abstract}

\section{Keywords-food safety; traceability system; system design}

\section{INTRODUCTION}

The meat product safety problems is food quality problems, how will the quality management of meat products, the most effective measure is the application of meat safety traceability system, which can not only improve the quality of meat products, but also to create a good environment for consumers. This paper mainly described the meat product safety traceability, application of meat products safety traceability system, and puts forward some constructive suggestions for the future development, in order to development of meat products safety traceability system application help.

\section{TRACEABILITY OF FOOD QUALITY AND SAFETY}

Clothing, food, shelter and transportation are the four most important things in life, it is more important to see food safety, and the application of meat products safety traceability system for food safety management has important significance.

First, it can allow consumers to really rest assured that consumption, I believe meat safety, etc., which is not only the responsibility of enterprises in the meat industry, but also the responsibility of the government. The global information technology today, the rapid development of science and technology, the meat product safety traceability system is also in constant reform progress, for ensuring the safety of meat products for import and export of meat products traceability system of management is not only the protection of the domestic consumer protection, but also the State export credit.

Second, strengthen the safety management of meat products emergency measures, the real meat quality and safety management, which is not only a fair and transparent consumer environment, but also a protection of the production side.
Third, to improve the level of animal health, to protect the safety of meat products. Traceability system can collect a local animal species, epidemic prevention and other detailed information, made of data information, when the problem can quickly find the source. Fourth, to meet the requirements of the current global market economy, with the international practice. In order to improve the credibility of meat products, countries around the world to strengthen the application of traceability system, and even some countries legislation enforcement. In order to occupy a space for one person in the world economic system, our country must be in accordance with international standards for the creation of the traceability system of meat products safety management in our country, to ensure meat products and health in China reached the standard specifications, promotion of meat products in China in the international market competitiveness.

\section{DeVelopment Process AND PRESENT Situation OF} FoOD SAFETY TRACEABILITY SySTEM AT HOME AND ABROAD

\section{A. Abroad}

In 2002, the Congress of the United States through the "biological terrorism act", this act under the guidance of the food and Drug Administration (FDA) has formulated a series of regulations, requirements of planting and production enterprises must establish a food safety traceability system. In 2004, FDA also issued the food safety tracking regulations, which requires all enterprises involved in food processing, transportation, distribution and import to establish and preserve the whole process of food chain records. The United States House of Representatives passed the 2009 Food Safety Enhancement Act in 2009, setting up a management plan for corrective action such as recall and traceability.

The Japanese government promulgated the "special measures for the individual identification of intelligence management law" in 2003, requiring animals from birth to establish information bar code, the sale of each piece of beef with a corresponding source of animal numbers label. In 2005, Japan established a food and agriculture product certification system, only the manufacturer, origin, date of receipt, the use of pesticides and names of agricultural products can enter the market sales.

\section{B. Internal}

Our country in learning based on foreign experience, continue to explore food safety traceability system for China's 
national conditions, has made some progress in food safety laws and regulations, regulatory agencies, traceability mode, established a system of food safety traceability management. In 2001, the Shanghai municipal government promulgated the "edible agricultural products safety supervision in Shanghai City Interim Measures": to establish safety and health quality of the production bases for tracking system, production base in the production activities, shall establish procedures of quality records, records of pesticide, fertilizer, animal medicine, feed and feed additives and epidemic prevention and quarantine etc., ensure product traceability. And provides for the establishment of agricultural products in the circulation of agricultural products safety and health. Since then, according to our country's food safety traceability system carried out a series of research, according to the International Association of published data encoding, and combined with the actual situation of our country, the initial development of the guidelines, such as the Chinese center has published articles encoding "beef product tracking and tracing guide", "fruit and vegetable traceability guide" etc..

\section{The Use of Key TeChNOLOgIES}

\section{A. Two Dimensional Code Technology}

The two-dimensional code technology is the one dimensional bar code data capacity is small, needs the backstage database to support and so on. Two-dimensional code can be expressed in text, images, audio and other information, all the information in the form of a twodimensional code after the summary of all stages of vegetables, code generation is convenient, no hardware equipment. Two dimensional code is divided into 40 sizes $(1 \sim 40)$, the official version of Version. The two-dimensional code size formula: $(\mathrm{V}-1) * 4+21$ (V version), version 1 is the size $(1-1) * 4+21$ $=21,21 * 21$ square minimum, the two-dimensional code shown in Figure I:

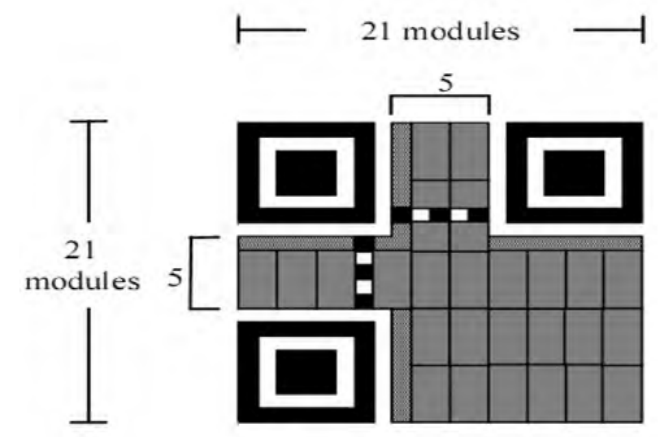

FIGURE I. VERSION 1 TWO DIMENSIONAL CODE

\section{B. RFID Technology}

RFID Technology is Radio Frequency Identification. It is a technique that is completely different from the bar code, does not need any equipment to read the product information, do not need to be like a bar code for optical contact. Radio signal reading target information is the main way of RFID technology. RFID technology is mainly composed of application software, transponder and reader. The main method is to use the reader to determine the frequency of radio, transponder operation, reader and then collect and analyze the relevant data. Exchange of data in this way. The advantage of RFID technology is that the reader can read, it can be tracked in real time, and there is no limit to the reading. In recent years, a lot of food safety industry in the use of the technology, enough to see its safety and practicality.

\section{Process Analysis of BeEF Cattle Traceability} SYSTEM

1) In the breeding farm sectors, including basic information registration, registration information, medication drinking cattle pig feed information registration, data submitted to the central database and other processes, which reported information including basic information, pig rearing plant basic information, health information etc.;

2) At slaughter links, including operators (consignor, buyer) entry filing, registration, registration of cattle slaughter batch, pre slaughter and post slaughter inspection and Quarantine Registration, transaction (default) information registration, data submitted to the central database process, which includes basic information reporting information, cattle slaughter plants, quarantine entry information the inspection information and transaction information such as meat;

3) In the distribution center (wholesale market) links, including entry operators (wholesalers and retailers) filing, registration, inspection of meat, meat trading information registration, the registration data submitted to the central database process, which includes basic information reporting information distribution center, site information, meat and meat meat inspection information transaction information etc.;

4) In the retail chain, including suppliers, Filing Certificate (slaughter factory or wholesale market transaction certificate) inspection, meat packing label (with traceability code) printing and information submitted to the central database and other processes, the reported information including retail stores basic information, enter information and meat meat sales information collection etc.

\section{FunCtion Module Design}

\section{A. User Management Module}

This module includes the administrator management and user management, the administrator is divided into super administrator and general manager, the general manager of the authority by the super administrator to distribution and its management, user registration information and audit related permissions set by the administrator.

\section{B. Basic Data Module}

This module is mainly operated by the administrator, on farms, slaughterhouses, distribution center (wholesale market) and data acquisition of the retail market for the collection, verification and storage, including the input information written to the information about the pig electronic tag, and the circulation node actively uploaded to the central database data source. 


\section{Data Query Module}

Consumers in the purchase of meat food, sweep using a mobile phone supermarkets, farms and other retail stores to provide two-dimensional code, we can get the meat sources, categories and shelf life of some of the basic information and the corresponding back yards, in addition to more detailed information, consumers can log on the system by virtue of the traceability code inquiry instruction detailed information about traceability system platform, associated with the meat back to the consumer.

\section{Data Release Public Module}

According to the results of the information statistical analysis module to form a statistical report, and in a friendly way to the consumer. At the same time will be based on the views and suggestions of consumers, will be the information of the consumer interest in real time to publish.

\section{E. Complaint Recommendation Module}

Consumers in the purchase of pork products, such as quality problems, complaints can be logged on to the system, the administrator will fill in the form according to consumer complaints, after verification, immediately make reasonable decisions, to ensure that consumers will minimize the losses.

Food safety traceability system design requirements using JAVA development, conforms to the J2EE specification, supports J2EE 1.3 and Java JDKI.4 and subsequent versions; the application system can run in WebLogic, WebSphere and other mainstream application server; all required software system in Linux operating system deployment; database adopts Server SQL 2008 version of the database. The introduction of two-dimensional code technology, three layer architecture of $\mathrm{B} / \mathrm{S}$ mode based on the development of this project; data sharing requirements in accordance with XML standard; data sharing requirements in accordance with SOA and services standard; for application of GIS display intuitive and flexible; require the use of independent development platform, complete system component development.

\section{CONCLUSION}

The application of two-dimensional code to the traceability system of meat products can effectively improve the traceability of the system. For consumers, by including in the two-dimensional code information, query information on food safety, food safety to obtain the latest information, protect the consumer's right to know; to the enterprise, through the twodimensional code food traceability, publish product information, accept consumer feedback, strengthen the management of food production and sales. The establishment of meat products safety traceability system is a powerful means to ensure food safety, safeguard the interests of consumers, but also the inevitable trend of the future development of meat products safety management.

\section{ACKNOWLEDGMENT}

Thank you for the support of Jilin Provincial Department of Education (NATURAL SCIENCE) Research Plan [2013] No. 288.

\section{REFERENCES}

[1] Papetti P, Costa C, Antonucci F, et al. A RFID web -based infotracing system for the artisanal Italian cheese quality traceability[J]. Food Control, 2012, 27(1):234-241.

[2] Schwagele F. Traceability from European perspective [J]. Meat Science, 2005, 71 (1):164-173.

[3] DU Wei. Application on food safe tracking system based on RFID [J].Food Science and Technology,2007(2):25-28.

[4] ZHAO Jin-yan,TAO Lin-li. Studies on animal food safety traceability system research based on RFID [J]. Journal of Yunnan Agricultural University, 2008,23(4):528-531.

[5] Yang Y S,Bao W X. The designation andimplementation of halal beef wholly quality traceability system[C].IFIP Advances in Information and Communication Technology: Series Volume 346. Berlin: Springer Berlin Heidelberg,2010: $464-472$. 